\title{
Analisa Kualitas Layanan Website PT. Masusskita United Menggunakan Metode Webqual
}

\author{
Audina Faza ${ }^{1 *}$, Agus Prasetyo Utomo², \\ ${ }^{1,2}$ Program studi Sistem Informasi, FTI, Universitas Stikubank, Semarang, Indonesia \\ E-mail: ${ }^{1, *}$ faza.audina@gmail.com, ${ }^{2}$ mustagus@edu.unisbank.ac.id
}

\begin{abstract}
Abstrak - PT MASUSSKITA UNITED adalah sebuah perusahaan yang bergerak dibidang Heavy Duty Industry. Peningkatan informasi melalui pemanfaatan website selaras perkembangan teknologi saat ini. Website perusahaan yang telah diimplementasikan menjadi pendorong dalam upaya meningkatkan informasi produk selama ini belum pernah dilakukan evaluasi, namun seiring perkembangan kebutuhan perusahaan yang bertambah, maka perusahaan merasa butuh untuk melakukan analisa sejauh mana kualitas layanan website mampu memberikan kepuasan dan loyalitas kepada pelanggannya. Metode webqual4.0 digunakan untuk mengukur kualitas layanan website www.masusskita.co.id dengan menambahkan variabel User Interface sebagai variabel independen dan variabel E-Customer Loyalty sebagai variabel dependen untuk melihat hubungan kepuasan pelanggan terhadap loyalitas. Penelitian ini bertujuan untuk mengetahui kepuasan dan loyalitas pelanggan terkait kualitas layanan website PT Masusskita United. Metode pengumpulan data menggunakan kuesioner dan memperoleh 161 responden. Pengolahan data statistik menggunakan SmartPLS 3.0. Hasil dari uji hipotesis yang menunjukan bahwa dari 5 hipotesis hanya 4 yang memiliki pengaruh yang signifikan dan 1 tidak signifikan. Secara bersama-sama Variabel Usability, User Interface, Service Interaction berpengaruh terhadap variabel E-Cutomer Satisfaction, dan pengaruh positif dan adanya pengaruh signifikan variabel E-Satisfaction terhadap variabel E-Customer Loyalty. Namun pengaruh positif variabel Information Quality tidak signifikan terhadap variabel E-Customer Satisfaction. Variabel User Interface memiliki signifikansi yang tinggi terhadap E-Customer Satisfaction.
\end{abstract}

Kata Kunci: Webqual4.0, PLS-SEM, Website, Kepuasan, Kualitas layanan, SmartPLS3.0

Abstract - PT MASUSSKITA UNITED is a company engaged in the Heavy Duty Industry. Through information on the use of websites in line with current technological developments. The company's website that has been implemented as a driver in efforts to improve product information has never been evaluated, but along with the development of increasing company needs, the company feels the need to analyze the extent to which the quality of website services is able to provide satisfaction and loyalty to its customers. The webqual4.0 method is used to measure the service quality of the www.masusskita.co.id website by adding the user interface variable as the independent variable and the loyalty variable as the dependent variable to see the relationship between customer satisfaction and loyalty. This study aims to determine customer satisfaction and loyalty related to the service quality of PT Masusskita United's website. The data collection method used a questionnaire and obtained 161 respondents. Statistical data processing using SmartPLS 3.0. The results of the hypothesis test show that of the 5 hypotheses only 4 have a significant effect and 1 is not significant. Together, the Usability, User Interface, and Service Interaction variables have an effect on the E-Customer Satisfaction variable, and there is a positive influence and the E-Satisfaction variable has a significant effect on the E-Customer Loyalty variable. However, the positive influence of the Information Quality variable is not significant on the E-Customer Satisfaction variable. User Interface variables have a high significance on E-Customer Satisfaction.

Keywords: Webqual 4.0, PLS-SEM, Website, E-Customer Satisfaction, Customer Loyalty, SmartPLS3.0.

\section{PENDAHULUAN}

Saat ini sistem informasi sudah menjadi bagian yang tidak bisa dilepaskan dari aktivitas-aktivitas manusia dalam kehidupannya, teknologi informasi atau sistem informasi mempunyai peran yang cukup penting untuk menunjang setiap aktivitas kehidupan manusia menjadi lebih efekif dan efisien, hal ini salah satunya dikarenakan hadirnya teknologi internet. Bahkan saat ini masyarakat sudah menjadikan internet menjadi bagian yang akan selalu ada dalam aktivitas masyarakat sehari-hari. Internet telah menjadikan interaksi manusia dalam berkomunikasi menjadi lebih mudah dan simpel, dan cepat tanpa harus dibatasi oleh ruang, jarak, dan waktu. Internet memiliki banyak keunggulan diantaranya adalah biaya akses relatif murah dan Informasi yang tersedia tidak terbatas. Untuk itu saat ini tidak bisa dipungkiri bahwa internet telah menjadi bagian utama dari kebutuhan yang ada di masyarakat dalam memenuhi segala kebutuhan yang berkaitan dengan informasi[1].

Perkembangan sistem informasi yang demikian pesat memberikan dampak pada perubahan layanan organisasi ataupun perusahaan[2]. Saat ini layanan kepada pengguna juga dapat dilakukan secara online, contohnya adalah perusahaan yang menjual barang/jasa melalui website perusahaannya. Dan memberikan layanan seperti informasi barang/jasa kepada calon pembeli secara online. Dalam hal ini peran website sudah menjadi bagian yang penting dari suatu bisnis termasuk perusahaan PT. Masusskita United terlebih lagi salah satu peran bisnis ini adalah sebagai 
pusat informasi bagi penjualan atau informasi produk yang ingin disampaikan kepada calon pelanggan. Dalam penelitian ini dilakukan pengukuran kualitas layanan website perusahaan PT. Masusskita United yang beralamat www.masusskita.co.id dengan menggunakan pendekatan metode Webqual 4.0 [3]. Metode ini sudah di kembangkan dari tahun 1998 dan beberapa kali telah mengalami beberapa perubahan dalam dimensi dan 14 item pertanyaan. Metode ini juga disusun berbasarkan penelitian pada tiga bagian, yaitu : (a) Kualitas informasi dari penelitian sistem informasi, (b) Interaksi dan kualitas layanan dari penelitian kualitas sistem informasi, (c) Usability dari interaksi manusia komputer (human computer interaction) [4]. Ketiga variabel yang digunakan pada Webqual 4.0 dapat menjawab permasalahan perusahaan dalam menjawab kebutuhan pelanggan terhadap kualitas website yang dikelola perusahaan e-commerce (Barnes dan Vidgen dalam Hasanah dkk, 2014). Peneliti menambahkan variabel User Interface sebagai variabel dependen untuk melihat apakah variabel ini juga memberikan pengaruh pada kepuasan pelanggan terhadap layanan website perusahaan.

Secara umum, loyalitas pelanggan berkaitan erat dengan keuntungan dan pertumbuhan jangka panjang suatu perusahaan. Kepuasan pelanggan yang tinggi berpengaruh besar terhadap loyalitas [5]. Namun, dampaknya cukup kompleks. Kepuasan pelanggan hanya mempengaruhi preferensi pelanggan dalam memilih penyedia layanan dan produk [6]. Kepuasan pelanggan terhadap website terkait erat dengan loyalitas [7]. Tujuan dari penelitian ini adalah untuk mengetahui hubungan persepsi konsumen terhadap kualitas layanan pada website www.masusskita.co.id dan untuk mengetahui hubungan signifikani antara tingkat kepuasan konsumen website terhadap dimensi kualitas layanan web yaitu; Usability (kemudahan), Information Quality (kualitas informasi), Interaction Quality (kualitas interaksi) dan User Interface (antarmuka pengguna).

\section{TINJAUAN PUSTAKA}

\subsection{Webqual4.0.}

Metode Webqual merupakan suatu pengukuran tingkat kualitas suatu website berdasarkan instrumen penelitian yang dapat dikategorikan menjadi variabel kualitas layanan website. [8]

Webqual dikembangkan sejak tahun 1998 yang merupakan pengembangan dari pengukuran kualitas metode ServQual. Webqual mengalami perkembangan dari versi 1.0 sampai versi saat ini versi 4.0 telah mengalami beberapa interaksi dalam penyusunan dimensi dan butir pertanyaan yang mengacu pada tiga dimensi utama pada kualitas sebuah website, yaitu : Usability, Information Quality, Service Interaction Quality[9][10].

\subsection{Structural Equation Modeling (SEM)}

Structural Equation Modeling (SEM) merupakan metode analisis multivariat yang dapat digunakan untuk menggambarkan keterkaitan hubungan linier secara simultan antara variabel pengamatan (indikator) dan variabel yang tidak dapat diukur secara langsung.

SEM merupakan teknik analisis multivariat yang dikembangkan guna menutupi keterbatasan yang dimiliki oleh model-model analis sebelumnya yang telah digunakan secara luas dalam penelitian statistik. Model-model yang dimaksud yaitu : analis regresi, analisi jalur, analisis faktor kondirmatori[11]

\subsection{Partial Least Square-Structural Equation Modeling (PLS-SEM)}

Partial Least Square-Structural Equation Modeling atau disebut dengan PLS-EM adalah metode SEM yang bisa memprediksi dengan kompleks model hubungan sebab-akibat dengan variabel laten.

Metode PLS tidak serumit yang ada pada di pemodelan SEM. PLS-SEM memberikan kelonggaran dalam penggunaan jumlah sampel yang tidak harus besar, selain itu, PLS juga memberikan kelonggaran pada peniliti untuk menggunakan skala pengukuran selain interval.

PLS-SEM dibuat untuk digunakan dalam regresi berganda ketika terjadinya suatu permasalahan spesifik pada data seperti adanya data yang hilang (missing values), dan lateral collinearity. Leteral collinearity yang tinggi dapat meningkatkan risiko secara penolakan hipotesis dalam pengujian regresi.[12]

\section{METODE PENELITIAN}

Penelitian ini dilakukan di PT. Masusskita United terkait persepsi pelanggan terhadap kualitas layanan websitenya. Jenis data yang diperlukan dalam penelitian ini adalah data primer dan data sekunder, baik dalam bentuk kuantitatif maupun kualitatif. Data primer diperoleh dari tanggapan responden dalam kuesioner yang disusun menjadi satu. 
Sedangkan data sekunder diperoleh dari studi literatur pada sejumlah publikasi ilmiah. Adapun metodologi dalam penelitian ini adalah sebagai berikut;

a. Memahami latar belakang masalah terkait kualitas layanan website di PT.Masusskita

b. Memilih prespektif teori untuk memahami konsep kualitas layanan website.

c. Membuat model penelitian dan hipotesisnya

d. Ontologi variabel, Dimensi, Indikator dan Scale

e. Membuat Kuesioner sebagai instrumen pengumpulan data

f. Pengumpulan data dengan menggunakan googleform.

g. Olah dan Analisis data dengan menggunakan Smart PLS

h. Temuan dan Implikasinya serta kesimpulan penelitian.

Penelitian ini menggunakan metode kuantitatif deskriptif. Metode deskriptif bertujuan untuk memberikan gambaran tentang suatu hal yang sedang berlangsung pada saat penelitian dan untuk menggambarkan secara tepat fakta dan hubungan yang terjadi antara fenomena yang diteliti [13]. Hal ini dilakukan untuk menjawab pertanyaan mengenai suatu situasi pada saat proses penelitian; yaitu menganalisis Information Quality, Usability, Service Interaction dan User Interface terhadap E-Customer Satisfaction dan E-Customer Loyality. Kerangka penelitian dijelaskan lebih lengkap pada Gambar 1. Model penelitian atau kerangka pikir yang akan digunakan dalam penelitian ini berdasarkan konsep-konsep Webqual 4.0 [14] adalah sebagai berikut :

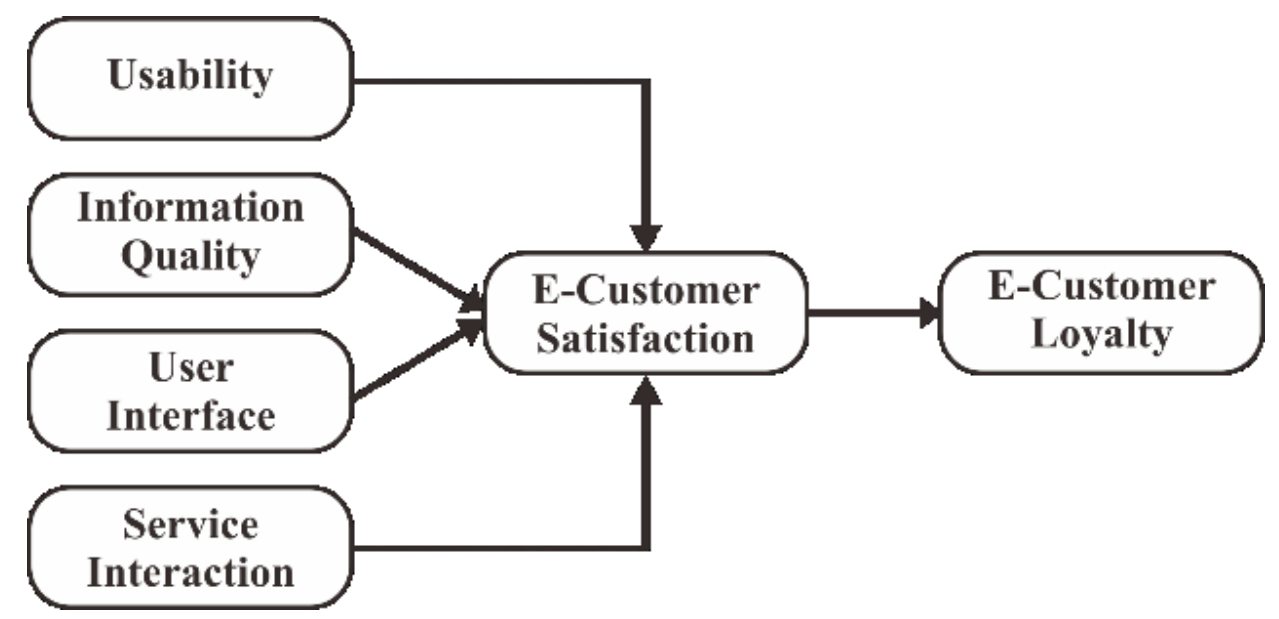

Gambar 1 - Model Struktural Penelitian

Hipotesis dalam penelitan ini adalah sebagai berikut:

$\mathrm{H} 1=$ Usability berpengaruh terhadap E-Customer Satisfaction.

H2 = Information Quality berpengaruh terhadap E-Customer Satisfaction.

H3 = User interface berpengaruh terhadap E-Customer Satisfaction.

H4 = Service Interaction berpengaruh terhadap E-Customer Satisfaction.

H5 = E-Customer Satisfaction berpengaruh terhadap E-Customer Loyalty.

Penelitian ini akan menggunakan teknik Webqual 4.0 untuk mengevaluasi kualitas website, pendekatan yang telah dilakukan dimodifikasi dari penelitian sebelumnya. Memiliki 4 dimensi kualitas layanan situs web untuk melihat pengaruhnya terhadap kepuasan dan loyalitas pelanggan. Berikut ini adalah varibel-variabel beserta atribut pengukuranya:

Usability: Pengalaman pengguna ketika berinteraksi dengan website, umumnya tentang efektivitas, efisiensi, dan kepuasan pengguna serta sejauh mana kemudahan dapat dirasakan oleh pengguna. Dengan atribut sebagai berikut:

1. Website mudah untuk digunakan

2. Navigasi nyaman dan mudah digunakan.

3. Tampilan website atraktif dan menarik

4. Alamat website mudah ditemukan

5. Penyusunan tata letak website disusun secara tepat

Information Quality: Persepsi pelanggan terhadap kualitas informasi produk dan layanan yang disediakan oleh website, dengan atribut sebagai berikut:

1. Informasi website tersedia dengan jelas 
2. Informasi website dapat dipercaya

3. Informasi website selalu up to date

4. Informasi website relevan

User Interface: Persepsi pelanggan terhadap kualitas antarmuka di situs web, dengan atrtibut sebagai berikut:

1. Website menggunakan gambar yang tepat.

2. Website menggunakan huruf yang tepat.

3. Website menggunakan warna yang tepat.

4. Desain halaman website tepat.

5. Fasilitas download bekerja dengan baik.

6. Tautan/link website bekerja dengan baik.

Service Interaction: Persepsi pelanggan terhadap kualitas interaksi di situs web, dengan atribut sebagai berikut:

1. Layanan Website mempunyai reputasi yang baik

2. Transaksi yang ada pada website aman.

3. Transaksi yang ada pada website nyaman

4. Website merespon feedback dengan baik

E-Customer Satisfaction: Kepuasan terhadap layanan yang diberikan, dengan atribut sebagai berikut:

1. Senang dengan layanan Website.

2. Situs website mudah digunakan.

3. Puas dengan layanan website secara keseluruhan

E-Customer Loyalty: Keinginan pelanggan untuk mengunjungi situs web lebih sering dan mempertahankan pembelian kembali, dengan atribut sebagai berikut:

1. Merekomendasikan untuk menggunakan layanan website kepada orang lain

2. Menyampaikan hal-hal positif tentang website kepada orang lain

3. Bermaksud untuk terus menggunakan website

Target responden penelitian ini adalah pelanggan PT Masusskita United yang minimal pernah melakukan akses dan interaksi di website sedikitnya satu kali kunjungan ke website. Pengumpulan data untuk penelitian ini menggunakan metode berupa kuesioner. Penyebaran kuesioner lamanya adalah 2 minggu dihitung pada tanggal 17 - 31 Maret 2021 dengan menggunakan googleform. Peneliti memperoleh data sebanyak 161 responden yang selanjutnya akan digunakan dalam pengolahan data secara statistik menggunakan SmartPLS 3.0.

Dalam penelitian ini dilakukan analisa data primer menggunakan statistik deskriptif dan statistik inferensial. Pada analisa statistik deskriptif, data responden diklasifikasi berdasarkan kota asal, jumlah kunjungan ke website, dan hasil data dari statistik deskriptif dari masing-masing variabel. Pada analisa inferensial dilakukan uji instrumen dengan mencakup uji validitas, uji reliabilitas. Dalam menguji uji validitas peneliti menggunakan metode convergent validity dan cronbach's alpha digunakan untuk uji reliabilitas[15].

\section{HASIL DAN PEMBAHASAN}

\subsection{Statistik Deskriptif}

\subsubsection{Statistik Deskriptif Responden}

Data penelitian ini berjumlah 161 responden yang merupakan pelanggan PT. Masusskita United. Statistik deskriptif responden meliputi kota asal pelanggan dan berapa kali pelanggan mengunjungi website.

Berdasarkan kota, responden terbanyak berasal dari Kota Jakarta sebanyak 33 orang atau sebesar $20.5 \%$ dari total keseluruhan, peringkat kedua adalah pengunjung dari Kota Surabaya sebanyak 22 orang atau 13.7\%, kemudian dari Kota Cilegon sebanyak 9 orang dengan presentase 5.6\%, dan kunjungan terkecil dengan presentase $0.6 \%$ berasal dari 14 kota yaitu, Banjarbaru, Banjarmasin, Banyumas, Boyolali, Cikarang, Cimahi, Kediri, Kotabaru, Kutai, Palembang, Palu, Pankajene \& Kepulauan, Paser, Pasuruan, Rembang, Samarinda, dan Situbondo.

Berdasarkan Jumlah kunjungan diketahui presentase terbesar adalah responden dengan jumlah kunjungan sebanyak 1-5 kali yaitu sebanyak 79 orang atau 49.1\%, urutan kedua 1 kali kunjungan dengan presentase $32.9 \%$ atau sebanyak 53 orang, jumlah kunjungan terbanyak $>10$ kali menempati urutan ke tiga dengan presentase $9.9 \%$ atau sebanyak 16 orang, dan responden dengan jumlah kunjungan 6-10 kali dengan presentase terendah yatu 8.1\% atau sebanyak 13 orang. 


\subsubsection{Statistik Deskriptif Variable}

Untuk memperoleh gambaran tentang kondisi kualitas layanan website PT. Masusskita United dilakukan pengujian perhitungan statistik deskriptif.

Dalam pemodelan ini digunakan 6 variabel dan 25 item, item-item digunakan untuk mengukur variabel. Penilaian terhadap item didapatkan dari respon terhadap pertanyaan-pertanyaan dalam kuesioner yang dibagikan dengan memakai skala likert dengan 5 tingkatan, yaitu:

a. Sangat tidak setuju (STS) berbobot 1

b. Tidak setuju (TS) berbobot 2

c. Netral (N) berbobot 3

d. Setuju (S) berbobot 4

e. Sangat Setuju (SS) berbobot 5

Peneliti mendefinisikan variabel Usability $\left(\mathrm{X}_{1}\right)$ dengan 5 item $\left(\mathrm{X}_{1.1}\right.$ sampai dengan $\left.\mathrm{X}_{1.5}\right)$, Information Quality $\left(\mathrm{X}_{2}\right)$ dengan 4 item $\left(\mathrm{X}_{2.1}\right.$ sampai dengan $\left.\mathrm{X}_{2.4}\right)$, User interface $\left(\mathrm{X}_{3}\right)$ dengan 6 item $\left(\mathrm{X}_{3.1}\right.$ sampai dengan $\left.\mathrm{X}_{3.6}\right)$, Service Interaction $\left(\mathrm{X}_{4}\right)$ dengan 4 item $\left(\mathrm{X}_{4.1}\right.$ sampai dengan $\left.\mathrm{X}_{4.4}\right)$, E-Customer Satisfaction $\left(\mathrm{Y}_{1}\right)$ dengan 3 item $\left(\mathrm{Y}_{1.1}, \mathrm{Y}_{1.2}\right.$, dan $\left.\mathrm{Y}_{1.3}\right)$, dan E-Customer Loyalty $\left(\mathrm{Y}_{2}\right)$ dengan 3 item $\left(\mathrm{Y}_{2.1}, \mathrm{Y}_{2.2}\right.$, dan $\left.\mathrm{Y}_{2.3}\right)$. Statistik deskriptif masing-masing variabel secara terperinci disajikan sebagai tabel berikut.

Tabel 1 - Statistik Deskriptif Variable

\begin{tabular}{l|l|l|l|l|l|r} 
& \multicolumn{1}{c}{ Missing } & \multicolumn{1}{c}{ Mean } & \multicolumn{1}{l}{ Median } & \multicolumn{1}{l}{ Min } & Max & Std. Deviation \\
\cline { 2 - 7 } $\mathrm{X}_{1.1}$ & 0.00 & 4.180 & 4.000 & 2.000 & 5.000 & 0.730 \\
$\mathrm{X}_{1.2}$ & 0.00 & 4.199 & 4.000 & 2.000 & 5.000 & 0.754 \\
$\mathrm{X}_{1.3}$ & 0.00 & 4.137 & 4.000 & 2.000 & 5.000 & 0.860 \\
$\mathrm{X}_{1.4}$ & 0.00 & 4.267 & 4.000 & 2.000 & 5.000 & 0.847 \\
$\mathrm{X}_{1.5}$ & 0.00 & 4.099 & 4.000 & 2.000 & 5.000 & 0.828 \\
$\mathrm{X}_{2.1}$ & 0.00 & 4.205 & 4.000 & 2.000 & 5.000 & 0.781 \\
$\mathrm{X}_{2.2}$ & 0.00 & 4.267 & 4.000 & 2.000 & 5.000 & 0.762 \\
$\mathrm{X}_{2.3}$ & 0.00 & 3.957 & 4.000 & 2.000 & 5.000 & 0.901 \\
$\mathrm{X}_{2.4}$ & 0.00 & 3.988 & 4.000 & 2.000 & 5.000 & 0.885 \\
$\mathrm{X}_{3.1}$ & 0.00 & 4.168 & 4.000 & 2.000 & 5.000 & 0.782 \\
$\mathrm{X}_{3.2}$ & 0.00 & 4.180 & 4.000 & 2.000 & 5.000 & 0.779 \\
$\mathrm{X}_{3.3}$ & 0.00 & 4.124 & 4.000 & 2.000 & 5.000 & 0.825 \\
$\mathrm{X}_{3.4}$ & 0.00 & 4.211 & 4.000 & 2.000 & 5.000 & 0.807 \\
$\mathrm{X}_{3.5}$ & 0.00 & 3.994 & 4.000 & 2.000 & 5.000 & 0.867 \\
$\mathrm{X}_{3.6}$ & 0.00 & 4.087 & 4.000 & 2.000 & 5.000 & 0.852 \\
$\mathrm{X}_{4.1}$ & 0.00 & 4.143 & 4.000 & 2.000 & 5.000 & 0.746 \\
$\mathrm{X}_{4.2}$ & 0.00 & 4.217 & 4.000 & 2.000 & 5.000 & 0.794 \\
$\mathrm{X}_{4.3}$ & 0.00 & 4.193 & 4.000 & 2.000 & 5.000 & 0.784 \\
$\mathrm{X}_{4.4}$ & 0.00 & 4.360 & 5.000 & 2.000 & 5.000 & 0.736 \\
$\mathrm{Y}_{1.1}$ & 0.00 & 4.230 & 4.000 & 2.000 & 5.000 & 0.750 \\
$\mathrm{Y}_{1.2}$ & 0.00 & 4.205 & 4.000 & 2.000 & 5.000 & 0.715 \\
$\mathrm{Y}_{1.3}$ & 0.00 & 4.267 & 4.000 & 2.000 & 5.000 & 0.786 \\
$\mathrm{Y}_{2.1}$ & 0.00 & 3.839 & 4.000 & 2.000 & 5.000 & 0.912 \\
$\mathrm{Y}_{2.2}$ & 0.00 & 3.994 & 4.000 & 2.000 & 5.000 & 0.895 \\
$\mathrm{Y}_{2.3}$ & 0.00 & 3.932 & 4.000 & 2.000 & 5.000 & 0.899 \\
\hline & & & & & &
\end{tabular}

Hasil olah data dari jawaban responden sebanyak 161 orang dari pengunjung website secara terperinci dijelaskan bahwa rata-rata dari setiap item pertanyaan mengenai variabel usability memperoleh nilai rata-rata 4 , dengan kata lain rata-rata pengunjung setuju bahwa website mudah untuk digunakan. Semenatara itu nilai rata-rata dari setiap item pertanyaan mengenai variabel Information Quality memperoleh nilai lebih besar dari 3 dan 4, 
dengan kata lain rata-rata pengunjung setuju bahwa website menyediakan informasi yang jelas dan dapat dipercaya atau kualitas informasi dipersepsi baik oleh pelanggan.

Nilai rata-rata dari setiap item pertanyaan mengenai variabel User Interface memperoleh nilai lebih besar dari 3 dan 4, dapat diartikan sebagai rata-rata pengunjung setuju dengan tampilan website dan interface website dipersepsi baik. Semantara itu rata-rata (mean) dari setiap item pertanyaan mengenai variabel Service Interaction memperoleh nilai lebih besar dari skala 4, dengan kata lain rata-rata pengunjung setuju jika menggunakan website PT. Masusskita United itu mempunyai layanan dengan reputasi yang baik.

Nilai rata-rata dari setiap item pertanyaan mengenai variabel E-customer Satisfaction memperoleh nilai lebih besar dari skala 4, dapat diartikan sebagai rata-rata pengunjung setuju bahwa pengguna website PT. Masusskita United itu merasa puas dengan layanan website secara keseluruhan. Semantara itu rata-rata dari setiap item pertanyaan mengenai variabel E-customer Loyalty memperoleh nilai lebih besar dari skala 3 dan cenderung mendekati skala 4, dengan kata lain rata-rata pengunjung bersikap netral namun cenderung mendekati setuju terkait loyalitas terhadap website PT. Masusskita United. Hal ini berarti loyalitas yang kuat dari pelanggan belum terbentuk dari kepuasan yang didapat dari kualitas layanan website perusahaan. Untuk itu perusahaan perlu melakukan inovasi-inovasi untuk melakukan perbaikan-perbaikan dalam layanan websitenya agar 4 dimensi kualitas layanan tersebut menjadi lebih baik lagi. Kualitas layanan yang semakin baik diharapkan akan meningkatkan kepuasan pelanggan yang pada akhirnya memberikan dampak pada loyalitas mereka.

\subsection{Statistik Inferensial}

\subsubsection{Skema Model Partial Least Square (PLS)}

Dalam pengujian ini aplikasi yang digunakan adalah program SmartPLS versi 3.0, dan gambar pemodelan Partial Least Square (PLS) adalah sebagai gambar berikut [16].

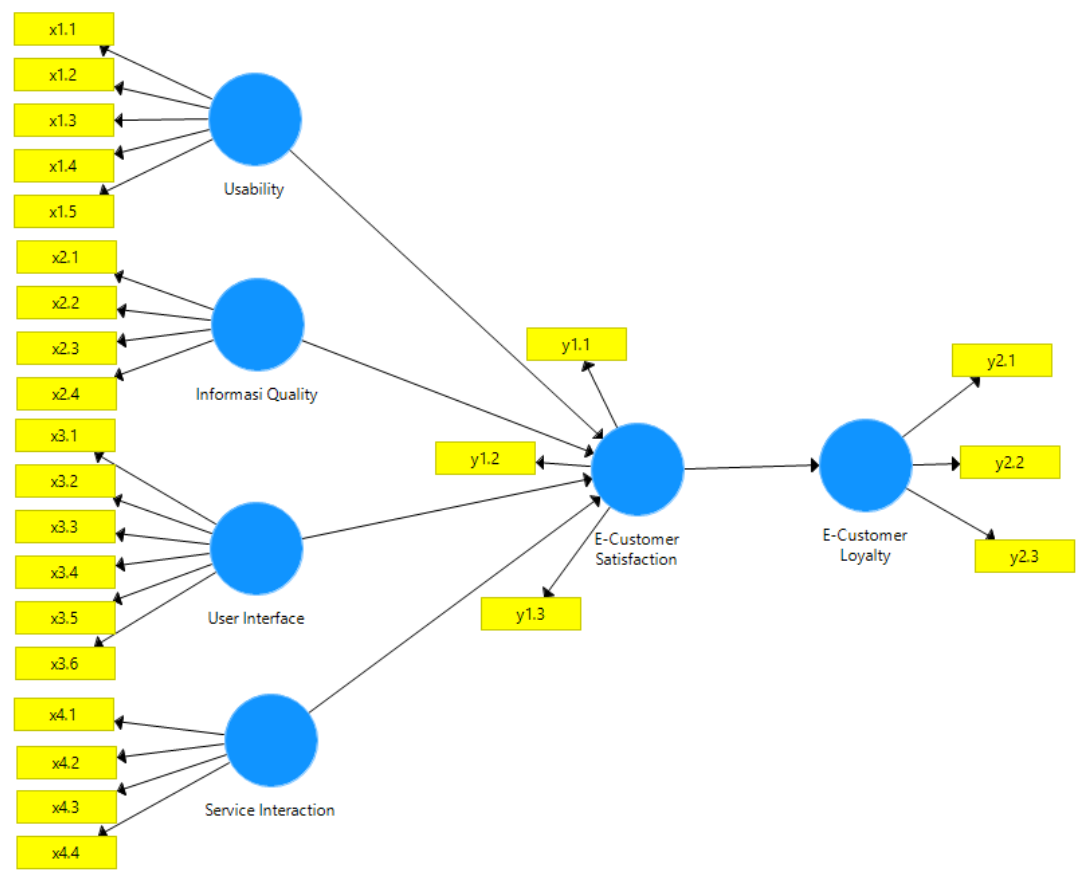

Gambar 2 - Pemodelan PLS

\subsubsection{Evaluation of Measurement Model}

Dalam penelitian ini pengujian validitas dan reliabilitas hanya dilakukan terhadap 161 responden. Pengambilan keputusan uji validitas berdasarkan pada nilai Factore Loading $>0,7$ serta untuk angka nilai Average Variance Extracted $(A V E)>0,5$ maka item-item tersebut dinyatakan valid.[12]. Pada pengambilan keputusan uji reliabilitas berdasarkan pada nilai Composite Reliability $>$ 0,7, dan nilai Croanbach's Alpha > 0,7, maka masing-masing variabel tersebut dikatakan reliable.[17] 


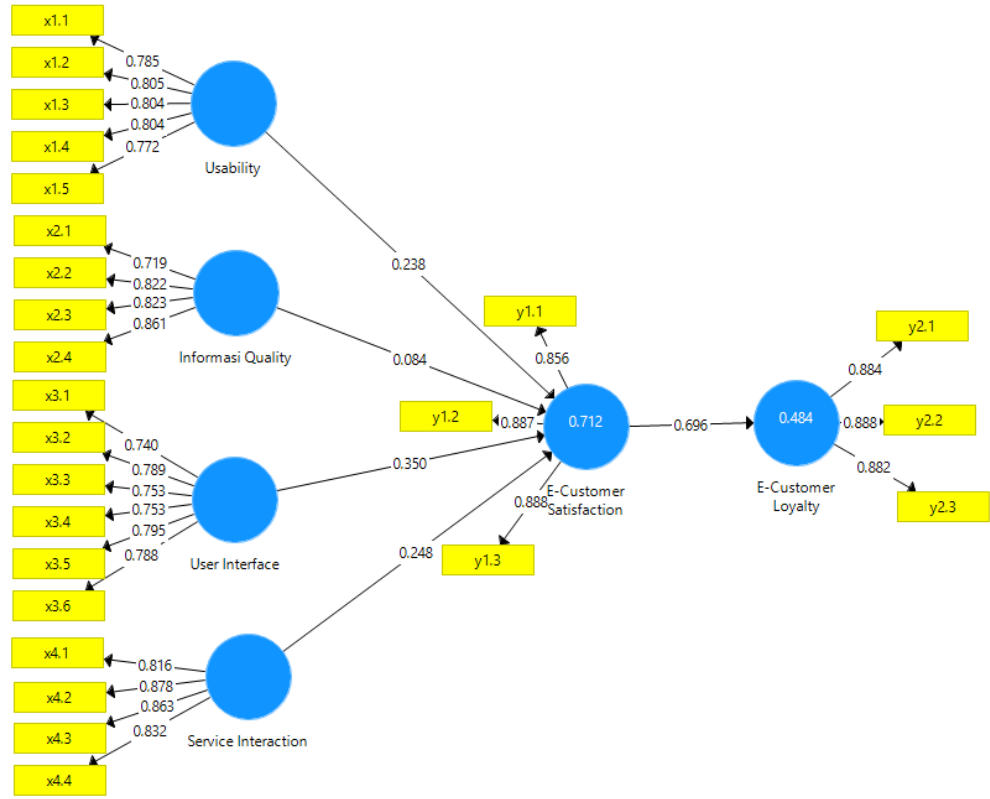

Gambar 3 - PLS Algorithm (Running)

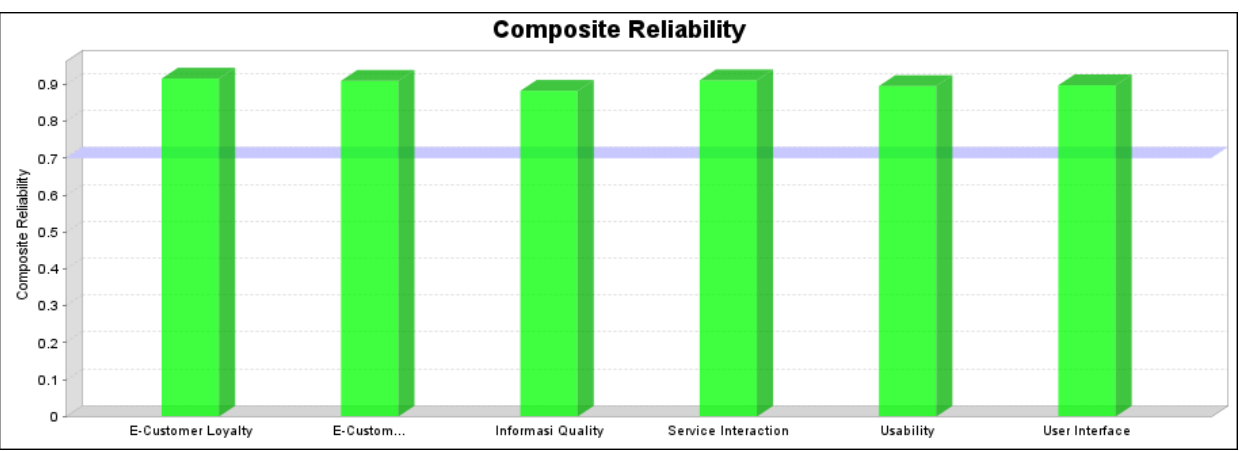

Gambar 4 - Composite Reliability

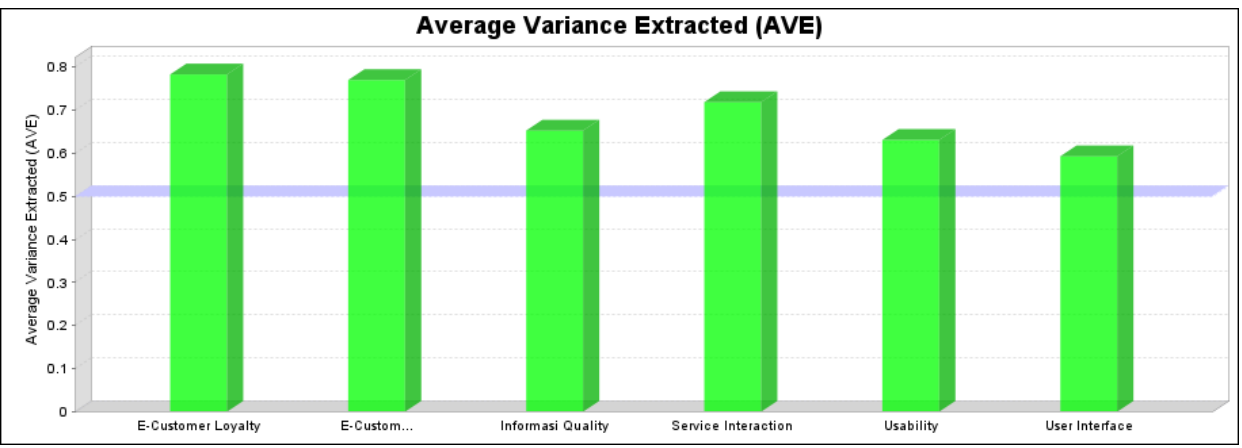

Gambar 5 - Avarage Variance Extracted (AVE) 


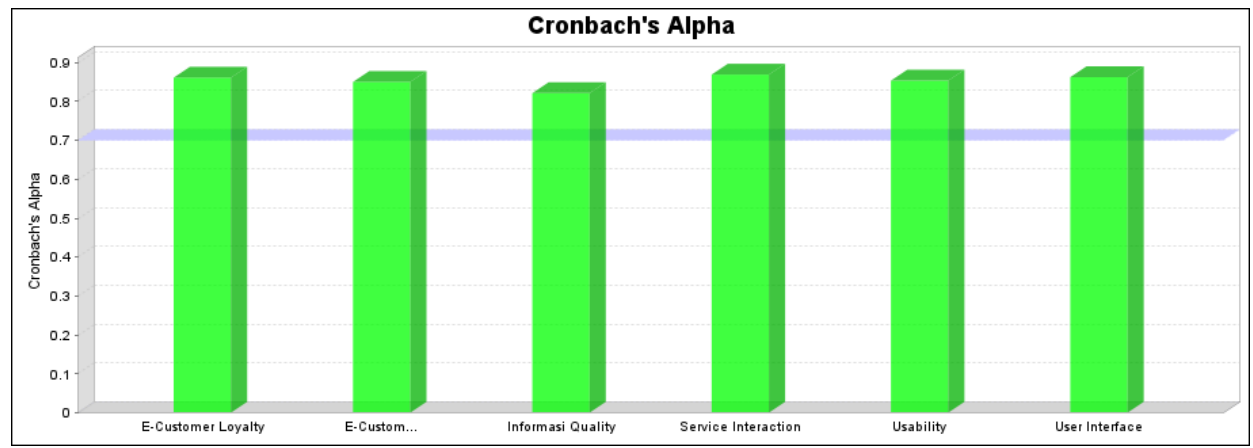

Gambar 6 - Cronbach's Alpha

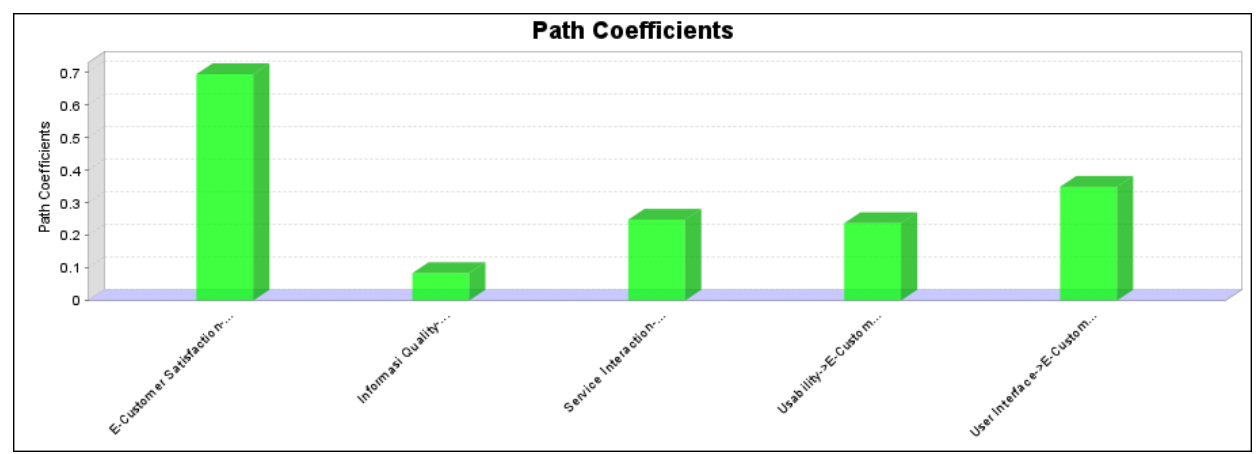

Gambar 7 - Path Coefficients

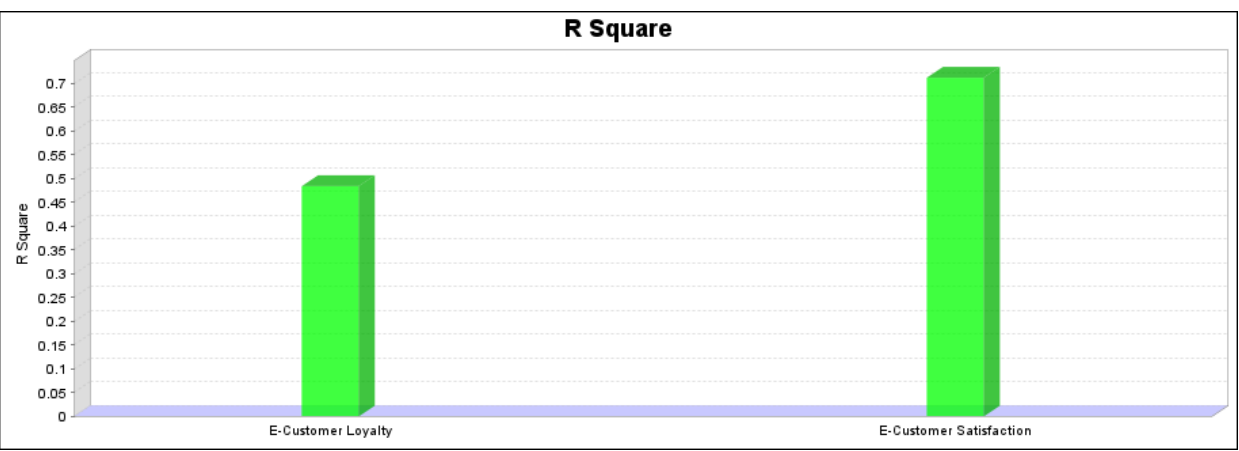

Gambar 8 - R Square

Tabel 2 - Outer Loadings

\begin{tabular}{ccc}
\hline Variable & Item & \multicolumn{1}{c}{ Outer Loadings } \\
\hline & 1 & 0.785 \\
Usability (X1) & 2 & 0.805 \\
& 3 & 0.804 \\
& 5 & 0.804 \\
& 5 & 0.772 \\
\hline Informasi & 1 & 0.719 \\
Quality (X2) & 3 & 0.822 \\
& 4 & 0.823 \\
& 1 & 0.861 \\
\hline & 2 & 0.740 \\
User interface & 3 & 0.789 \\
(X3) & 4 & 0.753 \\
& 5 & 0.753 \\
& 6 & 0.795 \\
& 1 & 0.788 \\
\hline
\end{tabular}




\begin{tabular}{ccc} 
Service & 2 & 0.878 \\
Interaction & 3 & 0.863 \\
$(\mathrm{X} 4)$ & 4 & 0.832 \\
\hline E-Customer & 1 & 0.856 \\
Satisfaction & 2 & 0.887 \\
(Y1) & 3 & 0.888 \\
\hline E-Customer & 1 & 0.884 \\
Loyalty (Y2) & 2 & 0.888 \\
\hline
\end{tabular}

Berdasarkan tabel 2, maka dapat dilihat bahwa semua item dari beberapa variabel memiliki nilai outer loadings $>0,7$, maka semua item dinyatakan valid. Berdasarkan dari gambar 5, maka dapat diartikan bahwa semua item memiliki validasi yang baik, karena nilai Average Variance Extracted (AVE) > 0,5 [18].

Berdasarkan gambar diagram 4, nilai Composite Reliability masing-masing variabel $>0,7$ maka dapat diartikan dari semua variabel tersebut memiliki status reliable.

Berdasarkan pada gambar 6, masing-masing variabel mempunyai nilai Cronbach's Alpha $>0,7$, maka dapat disimpulkan bahwa keseluruhan variabel memiliki atau memenuhi syarat [18].

\subsection{Evaluation of Structural Model}

Pengambilan keputusan untuk evaluasi $R$-Square atau evaluasi terhadap koefisien determinan berdasarkan pada nilai $r$-square $\geq 0,67$ maka variabel memiliki pengaruh yang substansial, nilai $r$-square $\geq 0,33$ dan $<0,67$ maka memiliki pengaruh moderat, dan jika nilai $r$-square $\geq 0,19$ dan $<0,33$ menandakan memiliki pengaruh lemah[13].

Berdasarkan gambar 8, pada nilai $R$-Square variabel E-Customer Satisfaction mempengaruhi variabel $E$ Customer Loyalty sebesar 0,484, maka bisa dikatakan nilai tersebut dikategorikan sebagai nilai pengaruh moderat. Variabel Usability, Informasi Quality, User Interface, dan Service Interaction secara bersama-sama mempengaruhi variabel E-Customer Satisfaction dengan nilai sebesar 0,712 dan nilai tersebut bisa dikategorikan sebagai nilai pengaruh yang substansial.

Evalusi Path Coefficient berfungsi untuk menunjukan arah hubungan dan seberapa berpengaruh antara variabel independen dengan variabel dependen[19]. Standart nilai pada path coeffiecien adalah nilai dalam rentan 1 sampai 1. Nilai $>0$ memiliki arah hubungan positif dan nilai yang $<0$ memiliki arah hubungan negatif.

Berdasarkan pada gambar 7, pada nilai path coeffiecient pada keseluruhan variabel miliki angka yang $>0$ dengan kata lain semua variabel memiliki arah hubungan yang positif. 


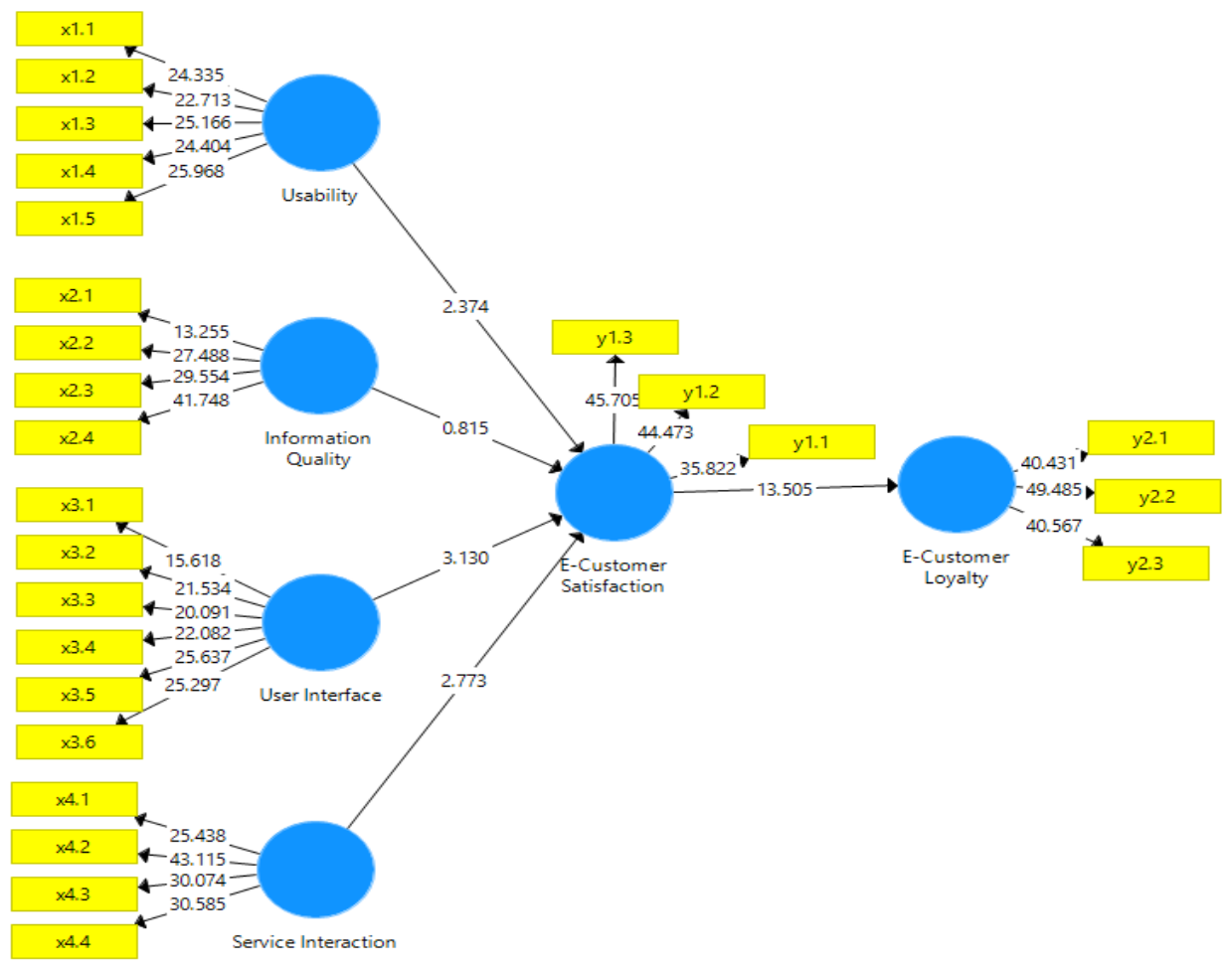

Gambar 9 - Bootstrapping T-Statistics

Pengambilan keputusan pada penguji hipotesis dengan tingkat signifikan 5\%, nilai t-statistics dikatakan signifikan bila nilai $>1,96$.

Merujuk pada gambar 9, pada nilai t-statistics diketahui pengaruh variabel Usability terhadap Variabel ECustomer Satisfaction memiliki nilai > 1,96 yaitu sebesar 2,374, pengaruh variabel Informasi Quality terhadap variabel E-Customer Satisfaction memiliki nilai $<1,96$ yaitu sebesar 0,815, pengaruh variabel User Interface terhadap variabel E-Customer Satisfaction memiliki nilai $>1,96$ yaitu sebesar 3,130, pengaruh variabel Service Interaction terhadap variabel E-Customer Satisfaction memiliki nilai $>1,96$ yaitu sebesar 2,773, dan pengaruh variabel E-Customer Satisfaction terhadap variabel E-Customer Loyalty memiliki nilai $>1,96$ yaitu sebesar 13,505.

Dari penjelasan hasil diatas terdapat variabel yang tidak signifikan atau memiliki nilai $<1,96$ yaitu variabel Information Quality terhadap variabel E-Csutomer Satisfaction dengan nilai sebesar 0,815. Sedangkan untuk hubungan variabel lainnya memiliki hubungan yang signifikan atau memiliki nilai $>1,96$. Varibel User interface memiliki pengaruh paling signifikan dibandingkan dari variabel yang lain dalam mempengarhui variabel $E$ Customer Satisfaction.

\subsection{Implikasi Manajerial}

Mengacu pada hasil penelitian tersebut, beberapa hal penting yang dapat diberikan kepada PT. Massuskita United terkait kualitas layanan websitenya, yaitu perusahaan dapat terus menjaga kepuasan pelangganya dengan berusaha untuk secara terus menerus meningkatkan kualitas layanan websitnya. Dengan kepuasan dan loyalitas pelanggan yang baik akan menjadikan website PT Masusskita United menjadi semakin terpercaya. Untuk menjaga reputasinya melalui layanan website, perusahaan juga dapat melakukan inovasi perbaikan yang berkelanjutan terkait kualitas informasi, usability, service interaction dan kualitas user interface web untuk menjaga pengakuan dari pelanggan. Dengan demikian, untuk meningkatkan loyalitas pelanggan, perusahaan dapat melakukan berbagai kegiatan promo produk secara visual di web. Selain itu juga dapat menempatkan semua informasi yang tercantum dengan cara-cara yang lebih menarik serta meningkatkan efektivitas fitur pencarian untuk lebih memudahkan pelanggan berinteraksi dengan website perusahaan. Varibel User Interface memiliki pengaruh paling signifikan terhadap variabel $E$ Customer Satisfaction, hal ini menjadi salah satu dimensi kualitas layanan yang perlu tetap dipertahankan dan terus menerus untuk ditingkatkan oleh perusahaan. Di sisi lain dimensi dari Information Quality perlu mendapatkan perhatian serius untuk menjadi prioritas dalam perbaikan kualitas layanan website perusahaan. 


\section{KESIMPULAN DAN SARAN}

\subsection{Kesimpulan}

Dari uraian pembahasan diatas dapat diambil kesimpulan sebagai berikut :

a. Variabel Usability memiliki pengaruh positif dan signifikan terhadap variabel E-Customer Satisfaction. Hipotesis pertama (H1) diterima.

b. Variabel Information Quality memiliki pengaruh positif namun tidak signifikan terhadap variabel E-Customer Satisfaction. Hipotesis kedua (H2) tidak diterima

c. Variabel User Interface memiliki pengaruh positif dan signifikan terhadap variabel E-Customer Satisfaction. Hipotesis ketiga (H3) diterima

d. Variabel Service Interaction memiliki pengaruh positif dan signifikan terhadap variabel E-Customer Satisfaction. Hipotesis keempat (H4) diterima

e. Variabel E-Customer Satisfaction berpengaruh terhadap variabel E-Customer Loyalty. Hipotesis kelima (H5) diterima.

f. Sikap positif dan ekspektasi terhadap pengunjung merupakan faktor penting terhadap tumbuhnya minat pengunjung untuk mengakses website PT. Masusskita United.

Penelitian ini bertujuan untuk menganalisis kepuasan dan loyalitas pelanggan terhadap website PT Masusskita United berdasarkan information quality, service interaction, usability, dan user interface. Berdasarkan hasil dan pembahasan disimpulkan bahwa kualitas informasi, usability, service interaction, dan user interface merupakan faktor-faktor yang mempengaruhi kepuasan dan kepercayaan pelanggan Massuskita; kualitas informasi berpengaruh terhadap kepercayaan tetapi tidak signifikan; pelanggan yang sudah memiliki kepercayaan terhadap PT Masusskita akan cenderung loyal.

\subsection{Saran}

Saran untuk penelitian selanjutnya dari hasil penelitian ini adalah:

a. Peneliti selanjutnya agar memperhatikan penyebaran kuesioner agar sampel penelitian dapat mewakili populasi secara merata.

b. Peneliti selanjutnya disarankan untuk mengukur pengaruh Service Interaction atau layanan kecepatan membalas pesan terhadap pengunjung website.

\section{DAFTAR PUSAKA}

[1] A. Mustopa, S. Agustiani, S. K. Wildah, and M. Maysaroh, "Analisa Kepuasan Pengguna Website Layanan Akademik Kemahasiswaan (LYKAN) UBSI Menggunakan Metode Webqual4.0,” J. Perspekt., vol. 18, no. 1, pp. 75-81, 2020, doi: 10.31294/jp.v18i1.7413.

[2] F. Carvalho, G. Santos, and J. Gonçalves, "The disclosure of information on sustainable development on the corporate website of the certified portuguese organizations," Int. J. Qual. Res., vol. 12, no. 1, pp. 253-276, 2018, doi: 10.18421/IJQR12.01-14.

[3] L. A. Utami, A. Ishaq, and N. Maulidiyah, "Analisa Pengaruh Kualitas Website PPDB Terhadap Kepuasan Pengguna," SinkrOn, vol. 3, no. 1, pp. 31-37, 2018, doi: 10.33395/sinkron.v3i1.10146.

[4] F. Titiani, Erni, D. Riana, C. Budi hartanti, S. Rahmatullah, and T. A. Tutupoly, "Analysis of User Satisfaction on Corona.Jakarta.go.id Website: Use WebqualMethod 4.0,” J. Phys. Conf. Ser., vol. 1641, no. 1, pp. 0-6, 2020, doi: 10.1088/1742-6596/1641/1/012015.

[5] Zins A, Relative attitudes and commitment in customer loyalty models: some experiences in the comercial airline industry. International Journal of Service Industry Management 12(3):269-294. 2001, doi.org/10.1108/EUM0000000005521

[6] Fisher A, Winning the battle for customers. Journal of Financial Sevices Marketing 6(2):77-93, 2001, doi.org/10.1057/palgrave. fsm.4770042.

[7] Cyr D, Modeling Website design across cultrues: relationship to trust, satisfaction and e-loyalty. Journal of Management Information Systmes 24(4):47-72, 2008, doi.org/10.2753/MIS0742- 1222240402.

[8] O. G. Hekhmatyar and D. Supriyadi, "Measurement Satisfaction Information System Quality Service On BSI Using WebqualAnd CSI," Indones. J. onComputer Inf. Technol., vol. 2, no. 2, pp. 1-6, 2017.

[9] R. R. Rerung, M. Fauzan, and H. Hermawan, "Website Quality Measurement of Higher Education Services Institution Region IV Using Webqual4.0 Method,” Int. J. Adv. Data Inf. Syst., vol. 1, no. 2, pp. 89-102, 2020, doi: 10.25008/ijadis.v1i2.185.

[10] Stuart J. Barnes Richard Vidgen, "Measuring Web site quality improvements: a case study of the forum on strategic management knowledge exchange", Industrial Management \& Data Systems, Vol. 103 Iss 5 pp. 297 - 309, 2003, 
doi.org/10.1108/02635570310477352

[11] A. Arfian, “Analisa Efektifitas Dan Kepuasan Penguna Website Kecamatan Jonggol,” J. Inkofar, vol. 1, no. 2, pp. 13-24, 2018, doi: 10.46846/jurnalinkofar.v1i2.13.

[12] A. Sauddin and N. S. Ramadhani, "Analisis Pengaruh Keterampilan Mengajar, Emosi Mahasiswa, Tekanan Akademik Dan Perceived Academic Control Terhadap Prestasi Akademik Mahasiswa Menggunakan Pendekatan Sem-Pls," J. MSA (Mat. dan Stat. serta Apl. ), vol. 6, no. 1, p. 6, 2018, doi: 10.24252/msa.v6i1.5063.

[13] Nazir. M, Metode Penelitian Cetakan Ketujuh. Bogor: Ghalia Indonesia, 2009.

[14] J. F. Andry, K. Christianto, and F. R. Wilujeng, "Using Webqual4.0 and Importance Performance Analysis to Evaluate E-Commerce Website,” J. Inf. Syst. Eng. Bus. Intell., vol. 5, no. 1, p. 23, 2019, doi: 10.20473/jisebi.5.1.2331.

[15] F. Yusup, “Uji Validitas dan Reliabilitas Instrumen Penelitian Kuantitatif,” J. Tarb. J. Ilm. Kependidikan, vol. 7, no. 1, pp. 17-23, 2018, doi: 10.18592/tarbiyah.v7i1.2100.

[16] M. Sarstedt, C. M. Ringle, and J. F. Hair, Handbook of Market Research, no. September. 2020.

[17] R. D. Parashakti and Putriawati, "Pengaruh Keselamatan Dan Kesehatan Kerja (K3), Lingkungan Kerja Dan Beban Kerja Terhadap Kinerja Karyawan,” J. Ilmu Manaj. Terap., vol. 1, no. 3, pp. 290-304, 2020, doi: 10.31933/jimt.v1i3.113.

[18] L. Sun, S. Ji, and J. Ye, Partial Least Squares. 2018.

[19] T. Ramayah, J. A. L. J. Yeap, N. N. H. Ahmad, H. Abdul-Halim, S. A. Rahman, and H. Halim, "Testing a Confirmatory model of Facebook Usage in SmartPLS using Consistent PLS,” Int. J. Bus. Innov., vol. 3, no. 2, pp. $1-14,2017$. 